\title{
CHALLENGES IN SHRIMP AQUACULTURE DUE TO VIRAL DISEASES: DISTRIBUTION AND BIOLOGY OF THE FIVE MAJOR PENAEID VIRUSES AND INTERVENTIONS TO AVOID VIRAL INCIDENCE AND DISPERSION
}

\author{
Caroline H. Seibert, Aguinaldo R. Pinto*
}

Departamento de Microbiologia, Imunologia e Parasitologia, Centro de Ciências Biológicas, Universidade Federal de Santa Catarina, Florianópolis, SC, Brasil.

Submitted: July 12, 2011; Approved: June 07, 2012.

\begin{abstract}
Shrimp aquaculture has been dramatically affected by many pathogenic diseases, mainly caused by five viruses: IHHNV, YHV, TSV, WSSV, and IMNV. Here we provide a state-of-the-art overview of these shrimp viruses, with emphasis on distribution, pathology, morphology, and genomic organization, in addition to current diagnostic methods and intervention practices.
\end{abstract}

Key words: shrimp aquaculture; viruses; diagnostic methods; disease control.

\section{INTRODUCTION}

In Latin American, Brazil is the third largest shrimpproducing country, being the States of Rio Grande do Norte, Ceará, and Pernambuco the major producers. However, despite the expressive growth in the Brazilian and world shrimp farming industry in the last decades, several pathogenic diseases have been reported to cause substantial economic losses. To date, more than twenty viral diseases have been reported to affect shrimp and prawns, and five viral pathogens of penaeid shrimp are currently listed by the World Organization for Animal Health (16). In this review, the distribution and biological characteristics of these five most significant viruses are profiled: infectious hypodermal and hematopoietic necrosis virus (IHHNV), yellow head virus (YHV), Taura syndrome virus (TSV), white spot syndrome virus (WSSV), and infectious myonecrosis virus (IMNV). The most valid diagnoses and interventions to avoid and contain viral dissemination are also further reviewed.

\section{MAJOR SHRIMP VIRUSES}

\section{Infectious hypodermal and hematopoietic necrosis} virus (IHHNV): The first widespread viral epizootic to seriously affect the commercial penaeid shrimp industry was IHHNV, also named Penaeus stylirostris densovirus (PstDNV), first reported in blue shrimps from Hawaii in 1980 (10). IHHNV has been identified in many other Pacific islands, as well as in the Americas from Peru to Mexico, East and Southeast Asia, Middle East, and Australia (16). IHHNVrelated sequences have been found inserted into the genome of P. monodon from India, Africa, and the Western Indo-Pacific region including Madagascar, Mauritius, and Tanzania.

\footnotetext{
*Corresponding Author. Mailing address: Departamento de Microbiologia, Imunologia e Parasitologia, Universidade Federal de Santa Catarina, 88040-900, Florianópolis, SC, Brazil.; Tel.: + 55-48-3721.5206 Fax: + 55-48-3721.9258.; E-mail: aguinaldo.pinto@ufsc.br
} 
Although IHHNV was first characterized as an agent of severe mortality in Litopenaeus stylirostris, it can infect other penaeid shrimp species such as $L$. vannamei and $P$. monodon in a less virulent form (10). Farfantepenaeus subtilis has also shown susceptibility under experimental challenges (16). Cumulative percentage mortality attributed to IHHNV infection can reach 90\% (10). Although L. stylirostris does not develop gross pathognomonic signs during IHHNV infection (10), L. vannamei and $P$. monodon develop a runt-deformity syndrome, with abnormalities such as bent or deformed rostrums, wrinkled walking legs, cuticular roughness, and other cuticular deformities. Histologically, viral occurrences are mainly in the cell nuclei from subcuticular epithelium of the mouth appendage, gill, thoracic ganglion, and nerve fiber of the walking leg, but can also occur sparsely in the cytoplasm (10).

IHHNV is classified as a member of the Parvoviridae family that is not formally classified but likely to be a member to the genus Brevidensovirus (19). IHHNV is a small, icosahedral, non-enveloped virion of $22 \mathrm{~nm}$ in diameter. The capsid is composed of four proteins (VP-1, -2, -3, and -4) with molecular weights of $74,47,39$, and $37.5 \mathrm{kDa}$, respectively (19). This virus possesses a single-stranded linear DNA genome comprising 4,100 nucleotides, which encompasses three large open reading frames (ORFs) on the complementary positive strand, referred to as left, mid, and right ORFs. The left ORF encompasses nucleotides 313 to 2,596 (2,284 nt), which encode a non-structural protein (NS-1) with replication initiator motifs, NTP-binding, and helicase domains. The middle ORF encompasses nucleotides 534 to 1,631 (1,098 nt), which overlap the left ORF and whose function remains unknown, possibly being another non-structural protein (NS-2). The right ORF overlaps the left ORF in 62 nucleotides and comprises nucleotides 2,535 to 3,527 (993 nt), probably encoding capsid proteins. Another potential coding domain encompassing nucleotides 1,726 to 1,022 (705 nt) is present in the complementary negative strand, and has the potential to encode a polypeptide of 134-aa (14.4 kDa) (19).
Yellow head virus (YHV): YHV, one of six known genotypes in the yellow head complex of viruses, was the cause of the second most serious viral epizootic of penaeid shrimp that occurred in Thailand in 1990 in cultured P. monodon. Since then, YHV has been reported in many shrimp-farming countries in Asia - including China, Taiwan, India, Indonesia, Malaysia, Philippines, and Vietnam - as well as in Mexico (16). Death of YHV-infected shrimp normally occurs within 3-5 days of the onset of disease clinical signs with cumulative mortality reaching up to $100 \%$ (1). Besides $P$. monodon, YHV can also cause serious mortality in L. vannamei. Indeed, there are multiple hosts for YHV, including many other penaeid shrimp species, palaemonid shrimp species and krill. In contrast, the palaemonid shrimps Macrobrachium rosenbergii and $M$. lanchesteri appear to resist against YHV infection and so do 16 species of crabs (16). Clinical signs caused by YHV infection are usually characterized by a pale-yellowish cephalothorax due to hepatopancreas and gill discoloration (1). Histologically, YHV infection is characterized by necrosis containing vacuolated cells with hypertrophied nuclei and basophilic viral inclusions in the cytoplasm of infected cells (1). Cellular necrosis occurs in connective tissues, hematopoietic and lymphoid organs, hemocytes, nerves, abdominal muscle, midgut, hepatopancreas, heart, but especially in head muscle, lymphoid organs, and gills.

YHV is classified in the Roniviridae family, genus Okavirus, within the Nidovirales order. YHV is an enveloped rod-shaped virion (approximately 40-50 x 150-170 nm) with prominent spike-like projections of $\sim 11 \mathrm{~nm}$ on the surface, and an inner helical nucleocapsid (27). The virion contains three major structural proteins with molecular masses of 116, 64 and $20 \mathrm{kDa}$. The first two proteins, named gp116 and gp64, are transmembrane glycoproteins of the envelope, and gp116 seems to be related to viral binding onto cell receptors; the 20 $\mathrm{kDa}$ protein, also named $\mathrm{p} 20$, is the major nucleocapsid protein (8). YHV genome is a positive-sense single-stranded RNA of approximately 26,662 nucleotides with a 3'-polyadenylated tail 
and four functional long ORFs (ORF-1a, -1b, -2, and -3) (20). ORF-1a and $-1 \mathrm{~b}$ are in overlapping frames by 37 nucleotides and encode non-structural proteins involved in viral replication and transcription. ORF-1a (12,219 nt) encodes a $\sim 463 \mathrm{kDa}$ polypeptide corresponding to proteases required for posttranslational processes of large polyproteins. ORF-1b $(7,887$ nt) encodes replication enzyme genes. Downstream ORF-1b is located ORF-2 (441 nt), which encodes a protein of 146-aa ( $\sim 20 \mathrm{kDa}$ ) corresponding to p20. The ORF-3 (4,998 nt) is immediately preceded by ORF-2 and encodes glycoproteins gp116 and gp64, which are generated by post-translational proteolytic cleavage of a $\sim 185 \mathrm{kDa}$ polypeptide. A fifth small ORF (ORF-4) is also located downstream from ORF-3, but does not appear to be functional (20).

Taura syndrome virus (TSV): TSV, one of the most important pathogens affecting farm-reared shrimp, was first reported in 1992 in L. vannamei collected from shrimp farms in Taura River, Ecuador (11). After its first report, TSV spread rapidly throughout the Americas, appearing in cultured penaeid shrimp stocks on the Pacific coast from Peru to Mexico, as well as on the Atlantic, Caribbean, and Gulf of Mexico coasts (16) In Southeast Asia, TSV was introduced in Taiwan in 1999, and since then the virus has spread through China, Thailand, Malaysia, and Indonesia. Cumulative mortality attributed to YHV infection can range from 50 to $90 \%$. Besides $L$. vannamei, TSV can infect several other shrimp species including P. monodon, Fa. aztecus, P. duorarum, L. setiferus, L. stylirostris, Marsupenaeus japonicus, M. rosenbergii, Metapenaeus ensis, F. chinensis, and L. schmitti. Moreover, three crab species, Sesarma mederi, Scylla serrata, and Uca vocans, have been infected experimentally (16). Acute phase clinical signs of TSV-infected shrimps are characterized by lethargy, anorexia, opaque musculature, and reddish discoloration in the tail fan and pleopods (11). During the recovery phase, animals present melanized cuticular lesions on the cephalothorax, tail, and appendages, although the clinical signs become undetectable in the chronic phase.
Histopathological evaluation reveals five main anatomic regions infected by TSV, including cuticle, gills, appendages, foregut, and hindgut; however, some individuals can present signs in abdominal muscle tissue. The disease is characterized by multifocal to diffuse necrosis, and the presence of eosinophilic and basophilic viral inclusions in the cytoplasm of infected cells.

TSV is a member of the Dicistroviridae family, consisting of a small, non-enveloped, icosahedral virion with 31-32 nm in diameter (13). Its genome contains 10,250 nucleotides in a single-stranded linear RNA of positive polarity, with two large non-overlapping ORFs separated by a 207-nucleotide intergenic region (13). ORF-1 encompasses nucleotides 417 to $6,737(6,321 \mathrm{nt})$ and encodes non-structural proteins including helicase, protease, and a RNA-dependent RNA polymerase. In contrast, ORF-2 encompasses nucleotides 6,947 to 9,979 $(3,033 \mathrm{nt})$ and encodes three capsid proteins: VP-1 (40 kDa), VP-2 (55 kDa), and VP-3 (24 kDa), being translated as a long polyprotein which is subsequently cleaved. A fourth polypeptide in minor concentration, VP-0 (58 kDa), is also observed in the TSV protein profile, and it may be produced by an alternative proteolytic cleavage of the capsid polyprotein (13). Although the TSV genome has been well characterized and the virion proteins have been identified, the function of these capsid proteins is still unknown.

White spot syndrome virus (WSSV): In 1992, a new virus appeared in shrimp farms in northern Taiwan causing massive mortality. Nowadays, WSSV, a rapidly replicating and extremely virulent pathogen, is the most serious diseasecausing agent in shrimp aquaculture worldwide. In fact, it has been identified in China, Japan, Korea, Southeast and Southern Asia, India, the Mediterranean, the Middle East, and the Americas (16). Cumulative mortality attributed to WSSV infection reaches $100 \%$ within $2-7$ days, and the virus has been detected in a wider range of species, including penaeid, palaemonid, and caridean shrimps, as well as lobsters, crabs, krill, crayfish, branchiopods, copepods, rotifers, polychaetes 
and coleopterons (5). WSSV-infected shrimps may rapidly develop white spots on the exoskeleton, epidermis, and appendages. Reddish discoloration is often observed, as well as enlargement and yellowish discoloration of hepatopancreas and loss of cuticle. Histologically, WSSV infection is characterized by eosinophilic to progressively basophilic viral inclusions in the hypertrophied nuclei of infected cells (3). Target cells include connective and epithelial tissues, hematopoietic nodules, hemocytes, gills, epidermis, stomach, striated muscles, and nerves.

WSSV is classified in the Nimaviridae family as the only known member of the Whispovirus genus (25). WSSV is a tailed, non-occluded virion with a tri-laminar lipid envelope and an ovoid to bacillary morphology, ranging in length from $210-420 \mathrm{~nm}$ and in diameter from $70-167 \mathrm{~nm}$ (4). The nucleocapsid exhibits asymmetric extremities, one round and another squared, measuring 180-420 nm in length and 54-85 $\mathrm{nm}$ in diameter. The WSSV virion has at least 58 structural proteins. Among them, 35 different proteins have been found in the envelope of the WSSV virion, with VP28 and VP26 as the most abundant proteins (22). WSSV possesses a large, circular, double-stranded DNA genome with $\sim 300,000$ nucleotides (25). Generally, different isolates exhibit up to $99 \%$ of genome identity; however, genome size may vary in as much as 13,000 nucleotides. The genome contains $\sim 184$ ORFs that encode functional proteins (25), and gene expression occurs in three phases during infection: immediate-early, early and late. So far 16 ORFs have been identified as immediate-early genes transcribed 1-2 hours post-infection (p.i.), encoding transcription factors, kinase, and ubiquitin E3 ligase (26). On the other hand, genes involved in nucleic acid metabolism, i.e. DNA polymerase, are transcribed 2-6 hours p.i., corresponding to early genes. At last, several WSSV late genes have been expressed 12 hours p.i., mainly structural proteins (26).

Infectious myonecrosis virus (IMNV): IMNV is the most recently emergent virus that infects Pacific white shrimps $L$. vannamei. Epizootic events due to IMNV infection were initially reported in 2002 in northeastern Brazil (12). Since the first outbreak, IMNV has spread to Southeast Asia, being reported in Indonesia. Cumulative mortality attributed to IMNV infection reaches from $40 \%$ to $70 \%$ (17). L. stylirostris, $P$. monodon and F. subtiltis also have shown to be susceptible to experimental infection (16). Typical clinical signs presented in IMNV-infected shrimp are focal to extensive opaque and whitish necrotic areas in the skeletal muscles, primarily in distal abdominal segments and tail fan (17). Histological injuries are characterized by coagulative muscle necrosis, often accompanied by fluid accumulation between muscle fibers, hemocytic infiltration, lymphoid organ spheroid formation and fibrosis (17). Darkly basophilic viral inclusions are seen within muscle cell cytoplasm, as well as in connective tissue cells and hemocytes. IMNV can be found in different tissues and organs such as skeletal muscle, lymphoid organ, hindgut, hepatopancreas, and heart (17).

IMNV is likely to be a member to Totiviridae family, and the first member of this family to infect a host other than fungus or protozoan $(15,17)$. IMNV is a non-enveloped virion with $40 \mathrm{~nm}$ in diameter whose icosahedral capsid has fibrous protrusions $(15,21)$. The long non-segmented double-stranded RNA genome (dsRNA), comprising two ORFs with 7,560 nucleotides, is arranged within the virion as 5-6 concentric shells $(17,23)$. ORF-1 encompasses nucleotides 136 to 4,953 $(4,818 \mathrm{nt})$, and is probably translated as a polyprotein which is subsequently cleaved into three fragments. The 93-aa (10 kDa) fragment shares similarities with dsRNA-binding proteins; the 1,228-aa fragment is probably cleaved afterwards, creating a 901-aa transcript of the major capsid protein $(99 \mathrm{kDa})$; the function of the third fragment $(284-\mathrm{aa}, 32 \mathrm{kDa})$ remains unknown. The ORF-2 comprises nucleotides 5,241 to 7,451 (2,211 nt), and encodes a putative RNA dependent RNA polymerase. Despite ORF-1 and ORF-2 being previously classified as non-overlapping regions, there is evidence that they overlap and are translated as a fusion protein of 1,734-aa $(\sim 196 \mathrm{kDa})$. 


\section{CURRENT DIAGNOSTIC METHODS}

Since there is currently no effective treatment for viral infections, preventive measures and practices are required to keep pathogens from spreading, and rapid diagnosis is one of the most effective strategies. Usually, clinical signs, immune parameters, and histopathological analyses are the first tests applied in order to evaluate animal health (12). However, these methods are not adequate for diagnosing, since a large number of factors can cause similar signs. For these reasons, more specific and sensitive diagnostic approaches have been developed, especially those employing molecular and immunologic tools.

Frequently, one of the first molecular techniques developed in order to diagnose shrimp viruses is in situ hybridization in tissue sections. However, the major disadvantage of this technique is the degradation of viral genome during fixation, especially in the detection of RNA viruses, contributing to false-negative results. Hence, more reliable results have been obtained using methods that identify viral genome by amplification procedures. The use of RTPCR/PCR technology, as well as nested RT-PCR/PCR, is an effective method in the screening of broodstocks and postlarvae. However, the amount of viral genome amplified by oneor two-steps of reaction may be lower than the detection limit, resulting in false-negative tests. In these cases, a quantitative measure is currently desirable and has been performed by realtime RT-PCR/PCR. Additionally, a novel molecular method to detect shrimp viruses is the reverse-transcriptase loop-mediated isothermal amplification reaction (RT-LAMP), followed by nucleic acid detection with a chromatographic lateral flow dipstick. This method confers specific, sensitive, and fast results, but it is yet not cost-efficient because of the expensive reagents used $(6,12)$.

In addition to molecular techniques, monoclonal antibodies have been elicited against shrimp viruses and used in the development of ELISA, immunoblotting, and immunohistochemistry, which are methods applicable in certified laboratories (6). Nevertheless, all these methods must be performed by well-trained personnel using specialized equipment, and are unsuited for pond-side detection. Assays developed as kits to be applied by farmers are the best strategy in viral detection, since the rapid dissemination of some viruses does not allow enough time to send samples to reference laboratories. Among the pond-side immunological tests, immunochromatographic strip tests are often the most requested because their application is simple and provides short-term results.

\section{MANAGEMENT, BIOSAFETY PRACTICES AND EXPERIMENTAL APPROACHES}

The enlargement of global shrimp culture has been followed by viral pandemic outbreaks, requiring the adoption of rigorous sanitation practices. Biosecurity methods involving prevention, control, and eradication of viruses in shrimp farms include disinfection of ponds, filtration of water, and treatment of effluents, in addition to monitoring the fluctuations of abiotic factors, such as oxygen, salinity, and temperature. Additionally, short-term interventions, such as the use of immunostimulants, vaccines, and RNA interference (RNAi), have been studied as attempts to induce resistance to viral infections.

Immunostimulants are compounds that enhance shrimp immune response non-specifically, providing resistance against viruses. Although several substances have been administered orally as immunostimulants in shrimp aquaculture, few reports have demonstrated their effects to prevent shrimp viral infections. Itami and colleagues (1998) evaluated the administration of peptidoglycan to $M$. japonicus shrimp during WSSV infection induced by water-borne route (7). The survival rates of shrimps challenged with WSSV ranged between $85 \%$ and $100 \% 40$ days after challenge. In addition, when $M$. japonicus was fed with lipopolysaccharide, the survival rates were $53-75 \%$ at 10 days after challenge with the same virus (21). Moreover, the feeding of $P$. monodon shrimp 
with herbal plants extract enhanced the survival up to $74 \% 20$ days after challenge with WSSV (2). However, the use of immunostimulants has a short-term effect, and it has been shown that their long-term use may affect growth rates, meat quality, or reproductive vigor.

Vaccination strategies also have been employed as an attempt to induce shrimp viral immunity, even knowing that invertebrates lack the sophisticated adaptive immune mechanisms present in vertebrates. Namikoshi and colleagues (2004) vaccinated $M$. japonicus shrimp intramuscularly with formalin-inactivated WSSV or with recombinant VP26 or VP28 (14). Vaccination with recombinant proteins induced longer resistance to challenge with WSSV than immunization with inactivated virus. Regardless of these valid results, the protection was not superior to 30 days post infection. In addition, Rout and colleagues (2007) demonstrated that $P$. monodon vaccinated with WSSV recombinant VP28- and VP281-envelope proteins conferred short-term protection for less than 3 weeks post-vaccination (18). However, when DNA plasmid vaccines encoding VP28- and VP281- genes were utilized as immunogen, the resistance against viral diseases was extended up to 7 weeks. Hence, long-term antigen expression through genetic immunization prolongs the protection, although it did not induce a persistent immune response. Moreover, much of the research on shrimp vaccination has focused on delivery by injection, which is impractical in field conditions, and oral vaccines have not demonstrated successful long-term resistance.

A new tool that has proved to be a feasible therapy against WSSV, TSV, and YHV is RNAi, a post-transcriptional genesilencing mechanism that leads to sequence-specific degradation of the viral mRNA. RNAi, first recognized as an antiviral response against RNA viruses, is a cellular mechanism that is activated by double-stranded RNAs (dsRNA) and results in the degradation of homologous genes. Tirasophon et al. (2007) demonstrated that the injection of YHV dsRNA to infected shrimp within 12 hours of the onset of infection completely abolished the viral multiplication and prevented shrimp mortality, showing the potential usefulness of RNAi to treat shrimp post-infection (24). Moreover, a potential application of RNAi is in the treatment of infected larvae or mature female broodstocks to generate virus-free shrimp progeny. However, issues of safety and public acceptance of a genetic engineering technique must be considered for future application in field trials. Indeed, although immunostimulants, vaccines, and RNAi provide promising results in laboratory studies, the use of all these methods in the field may not be reliable, especially because of limitations in terms of their efficacy, practicality, cost and reproducibility.

\section{CONCLUDING REMARKS}

Despite current progress in the shrimp industry over the past decades, many outstanding needs still remain to be fulfilled. Several issues related to the interaction between viruses and their hosts must be investigated, as well as the improvement of biosecurity practices. A wide range of diagnostic tests, especially those for on-farm use, must be available to better control viral spread. The applicability of immunostimulants in full-scale field trials and the understanding of the underlying protection mechanisms by vaccines or RNAi therapy must be better studied to guarantee the feasibility and cost-effectiveness of these interventions. In this scenario, the shrimp farming industry will evolve in a sustainable and safe system, reducing losses in production due to viral diseases.

\section{ACKNOWLEDGEMENTS}

The authors are grateful to Luciane M. Perazzolo for critically reading the manuscript, and to Conselho Nacional de Desenvolvimento Científico e Tecnológico (CNPq) for financial support.

\section{REFERENCES}

1. Chantanachookin, C.; Boonyaratpalin, S.; Kasornchandra, J.; 
Direkbusarakom, S.; Ekpanithanpong, U.; Supamataya, K.; Sriurairatana, S.; Flegel, T.W. (1993). Histology and ultrastructure reveal a new granulosis-like virus in Penaeus rnonodon affected by yellow-head virus. Dis. Aquat. Org. 17, 145-157.

2. Citarasu, T.; Sivaram, V.; Immanuel, G.; Rout, N.; Murugan, V. (2006). Influence of selected Indian immunostimulant herbs against white spot syndrome virus (WSSV) infection in black tiger shrimp, Penaeus monodon with reference to haematological, biochemical and immunological changes. Fish Shellfish Immunol. 21(4), 372-384.

3. Durand, S.; Lightner, D.V.; Nunan, L.M.; Redman, R.M.; Mari, J.; Bonami, J.R. (1996). Application of gene probes as diagnostic tools for white spot baculovirus (WSBV) of penaeid shrimp. Dis. Aquat. Org. 27:59-66.

4. Durand, S.; Lightner, D.V.; Redman, R.M.; Mari, J.; Bonami, J.R. (1997). Ultrastructure and morphogenesis of White Spot Syndrome Baculovirus (WSSV). Dis. Aquat. Org. 29, 205-211.

5. Escobedo-Bonilla, C.M.; Alday-Sanz, V.; Wille, M.; Sorgeloos, P.; Pensaert, M.B.; Nauwynck H.J. (2008). A review on the morphology, molecular characterization, morphogenesis and pathogenesis of white spot syndrome virus. J. Fish Dis. 31, 1-18.

6. Flegel, T.W. (2006). Detection of major penaeid shrimp viruses in Asia, a historical perspective with emphasis on Thailand. Aquaculture 258, 133 .

7. Itami, T.; Asano, M.; Tokishige, K.; Kubono, K.; Nakagawa, A.; Takeno, N.; Nishimura, H.; Maeda, M.; Kondo, M.; Takahashi, Y. (1998). Enhancement of disease resistance of kuruma shrimp, Penaeus japonicus, after oral administration of peptidoglycan derived from Bifidobacterium thermophilum. Aquaculture. 16, 277-288.

8. Jitrapakdee, S.; Unajak, S.; Sittidilokratna, N.; Hodgson, R.A.J.; Cowley, J.A.; Walker, P.J.; Panyim, S.; Boonsaeng, V. (2003). Identification and analysis of gp116 and gp64 structural glycoproteins of yellow head nidovirus of Penaeus monodon shrimp. J. Gen. Virol. 84, 863-873.

9. Li, F.; Li, M.; Ke, W.; Ji, Y.; Bian, X.; Yan, X. (2009). Identification of the immediate-early genes of white spot syndrome virus. Virology. 385 , 267-274.

10. Lightner, D.V.; Redman, R.M.; Bell, T.A. (1983). Infectious hypodermal and hematopoietic necrosis, a newly recognized virus disease of penaeid shrimp. J. Invertebr. Pathol. 42, 62-70.

11. Lightner, D.V.; Redman, R.M.; Hasson, K.W.; Pantoja, C.R. (1995). Taura syndrome in Penaeus vannamei (Crustacea: Decapoda): gross signs, histopathology and ultrastructure. Dis. Aquat. Org. 21, 53-59.

12. Lightner, D.V.; Poulos, B.T.; Tang-Nelson, K.F.; Pantoja, C.R.; Nunan, L.M.; Navarro, S.A.; Redman, R.M.; Mohney, L.L. (2006). Application of molecular diagnostic methods to penaeid shrimp diseases: advances of the past 10 years for control of viral diseases in farmed shrimp. Dev Biol (Basel).126, 117-122.

13. Mari, J.; Poulos, B.T.; Lightner, D.V.; Bonami, J.R. (2002). Shrimp
Taura syndrome virus, genomic characterization and similarity with member of the genus Cricket paralysis-like viruses. J. Gen. Virol. 83, 915-926.

14. Namikoshi, A.; Wu, J.L.; Yamashita, T.; Nishizawa, T.; Nishioka, T.; Arimoto, M.; Muroga, K. (2004). Vaccination trials with Penaeus japonicus to induce resistance to white spot syndrome virus. Aquaculture. 229, 25-35.

15. Nibert, M.L. (2007). '2A-like' and 'shifty heptamer' motifs in penaeid shrimp infectious myonecrosis virus, a monosegmented double-stranded RNA virus. J. Gen. Virol. 88, 1315-1318.

16. OIE - World Organization for Animal Health. (2009). Manual of Diagnostic Tests for Aquatic Animals 2009. OIE, Paris.

17. Poulos, B.T.; Tang, K.F.J.; Pantoja, C.R.; Bonami, J.R.; Lightner, D.V. (2006). Purification and characterization of infectious myonecrosis virus of penaeid shrimp. J. Gen. Virol. 87, 987-996.

18. Rout, N.; Kumar, S.; Jaganmohan, S.; Murugan, V. (2007). DNA vaccines encoding viral envelope proteins confer protective immunity against WSSV in black tiger shrimp. Vaccine. 25, 2778-2786.

19. Shike, H.; Dhar, A.K.; Burns, J.C.; Shimizu, C.; Jousset, F.X.; Klimple, K.R.; Bergoin, M. (2000). Infectious hypodermal and hematopoietic necrosis virus of shrimp is related to mosquito brevidensoviruses. Virology. 277, 167-177.

20. Sittidilokratna, N.; Dangtip, S.; Cowley, J.A.; Walker, P.J. (2008). RNA transcription analysis and completion of the genome sequence of yellow head nidovirus. Virus Res. 136(1-2), 157-165.

21. Takahashi, Y.; Kondo, M.; Itami, T.; Honda, T.; Inagawa, H.; Nishizawa, T.; Soma, G.I.; Yokomizo, Y. (2000). Enhancement of disease resistance against penaeid acute viraemia and induction of virus inactivating activity in haemolymph of kuruma shrimp, Penaeus japonicus, by oral administration of Pantoea agglomerans lipopolysaccharide (LPS). Fish Shellfish Immunol. 10(6), 555-558.

22. Tang, X.; Wu, J.; Siravaman, J.; Hew, C.L. (2007). Crystal structures of major envelope proteins VP26 and VP28 from white spot syndrome virus shed light on their evolutionary relationship. J. Virol. 81, 67096717.

23. Tang, J.; Ochoa, W.F.; Sinkovits, R.S.; Poulos, B.T.; Ghabrial, S.A.; Lightner, D.V.; Baker, T.S.; Nibert, M.L. (2008). Infectious myonecrosis virus has a totivirus-like, 120-subunit capsid, but with fiber complexes at the fivefold axes. Proc. Natl. Acad. Sci. USA. 105, 17526-17531.

24. Tirasophon, W.; Yodmuang, S.; Chinnirunvong, W.; Plongthongkum, N.; Panyim, S. (2007). Therapeutic inhibition of yellow head virus multiplication in infected shrimps by YHV protease dsRNA. Antiviral Res. 74, 150-155.

25. van Hulten, M.C.; Witteveldt, J.; Peters, S.; Kloosterboer, N.; Tarchini, R.; Fiers, M.; Sandbrink, H.; Lankhorst, R.K.; Vlak, J.M. (2001). The white spot syndrome virus DNA genome sequence. Virology. 286, 7-22.

26. Wang, H.C.; Lin, A.T.; Yii, D.M.; Chang, Y.S.; Kou, G.H.; Lo, C.F. 
(2003). DNA microarrays of the white spot syndrome virus genome: genes expressed in the gills of infected shrimp. Mar. Biotechnol. 6, 106111.

27. Wongteerasupaya, C.; Sriurairatana, S.; Vickers, J.E.; Akrajamorn, A.;
Boonsaeng, V.; Panyim, S.; Tassanakajon, A.; Withyachumnarnkul, B.; Flegel, T.W. (1995). Yellow-head virus of Penaeus monodon is an RNA virus. Dis. Aquat. Org. 22, 45-50. 